\title{
SELECTED APPROACHES OF THE BEHAVIORAL ECONOMICS IN POST PANDEMIC MANAGEMENT
}

\author{
Norbert Súkeník ${ }^{1 *}$, Nadežda Jankelová ${ }^{1}$ \\ ${ }^{1}$ University of Economics in Bratislava, Faculty of Business Management, Management Department, \\ Dolnozemská cesta 1, Bratislava, Slovakia
}

\begin{abstract}
Changes in organizational behavior, decision-making processes, human thinking and action are the subject of an exploration of the increasingly popular behavioral economy. We assume that her knowledge gained from various economic or psychological experiments in recent decades can help managers understand the specifics of human behavior and action. The Covid crisis and the pitfalls it brings pose new challenges for managers. Knowledge of behavioral economics and descriptive approaches to decision making allows us to understand how people act in real conditions. This knowledge can help managers streamline management and become better leaders. The paper deals with the benefits of behavioral economics for managers in the process of "reopening" the economy and its main goal is to highlight the knowledge and solutions of behavioral economics, usable for postpandemic management. To meet the goal, it is necessary to describe the changes and new specifics of the environment affected by the pandemic crisis in the first, theoretical part of the work. After analyzing these changes and evaluating them, we look for the answers offered by behavioral economics in the final part of the paper. Based on the empirically obtained knowledge of mainly foreign authors, we present several examples of their practical application in the newly created management environment.
\end{abstract}

\section{Introduction}

The COVID-19 pandemic has brought many changes. The personal and professional lives of most people on Earth have begun to transform dramatically. The oftenly involuntary transition to "homeoffice" brought about by the pandemic was the biggest shock to many organizations. If they did not want to forcibly suspend or terminate their activities, they had to reconsider their organizational habits and adapt them to the new conditions. Until then, teleworking was the domain of multinational companies and "freelancers". The advent of the pandemic and its associated constraints have created pressure that has led to a global change in the organization of work. Companies that have so far avoided digitalization have had to start building a technological infrastructure adapted to operate "online". Only the data that is still being collected will show how effectively

\footnotetext{
${ }^{*}$ Corresponding author: norbert.sukenik@euba.sk
} 
companies have dealt with this obstacle. What is certain, however, is that almost all organizations have made significant changes. We are not yet able to predict which strategies and tactics will prove to be the most effective. Some changes will be permanent and some will gradually disappear. It is how to set up processes for the future, how to learn from a pandemic crisis and how to reopen and start a business is becoming the most pressing question today. Company managers must think strategically, with a view to the future.

The problems that come with "reopening" will require quality solutions. We do not know for sure to what extent it was possible to predict the beginning of the Covid crisis, but it is very likely that it will end once. Due to the high frequency of vaccinations, some countries are rapidly reaching or overcoming the inflection point, and the issue of reopening is becoming more and more relevant every day. We cannot forget that every problem is both a challenge and often a new opportunity to succeed.

The organization is based on the people who make it up. The more companies relied on technology to move to distance forms of work, the more they would have to rely on their people to return to some of the original patterns of work organization. The same employees may be physically returning to workplaces, but each of them has experienced the consequences of the pandemic spread of a dangerous virus in the past. In terms of their behavior, significant changes could have occurred. It is the manager's job to be able to respond to these changes.

\section{Theoretical Background}

\subsection{The impact of a pandemic on the social climate and the behavior of individuals}

The COVID-19 pandemic has so far infected more than 140,000,000 people, resulting in more than 3,000,000 deaths [1]. The relatively high infectivity and mortality rates for COVID-19 have forced countries to adopt new, unique approaches to preventing, suppressing and reducing the spread of the virus. The strategies used to the greatest extent are to wear protective face masks [2], monitor contacts [3] and shut down the economy $[4,5]$.

One of the most controversial of these measures is economic shutdowns. These aim to reduce the risk of the virus spreading, especially through the air in workplaces where employees are in direct contact with each other or with the customer [4,6]. During an economic downtime, some employees may still work from home, especially in office positions. However, it is not possible to provide work from home for a large group of workers, especially for manual positions. While wearing a protective mask or monitoring contacts causes minimal economic damage [3], economic downtime causes major losses and leads to the greatest global recession since the Great Depression [7]. These losses cause the greatest harm to people working in the labor professions, as they are people from lowincome groups and are therefore the least likely to have sufficient financial reserves [8-10]. This can put pressure on people and lead more often to fault behaviour.

Many scientists attribute the success of some countries in fighting the corona virus to a strategy of shutting down the economy, and it is undeniable that economic downtime is actually saving lives. However, they also result in economic losses which, through the ripple effect, cause other harmful consequences, such as a deterioration in the mental health of the population [5,6]. For this reason, during the COVID-19 pandemic, people developed strong attitudes towards economic shutdowns, so in the press, on social media and various 
professional or less professional discussion forums we can see strong arguments for and against economic shutdowns [5,11,12]. These attitudes collectively advance political decisions, but also encourage individual action. Lockdowns are most effective when all are governed by government regulations, but differing attitudes to the subject have led many individuals and organizations to disobey the order to suspend economic activity $[13,14]$. Disobedience ranges from disrespecting work from home to widespread public protests. Regardless of the belief in the appropriateness of economic shutdowns, they are exponentially less effective when people refuse to follow guidelines. Disobedience is only one consequence of the pandemic crisis, but it is also an illustrative example of how COVID-19 leads to behavioral changes that managers will have to cope with during reopening. It is the attitudes and behavior of employees that are studied by behavioral economics.

Undesirable behavioral abnormalities are likely to occur much more frequently after reopening in the workplace than before a pandemic broke out. It is the manager's job to monitor these deviations and to be prepared to take concrete steps to ensure the required behavior and safe return of the business to full operation.

\subsection{Managerial challenges in the workplace after reopening}

"From time to time, organizational environments undergo cataclysmic upheavals changes that are so sudden and far-reaching that they change the trajectories of entire industries, overcome the adaptive capacities of resilient organizations, and transcend the understanding of seasoned managers. " [15]

More efficient management and use of business resources in the post-pandemic era may require organizational hybridity, which involves the integration of different strategies, logics, and structural forms (eg, structural flexibility) to handle complex problems. In addition, companies need flexibility to effectively design and implement strategic changes, which requires fluidity, speed and setup that fosters innovative thinking and resilience [16]. This effort depends significantly on the dynamic capabilities of company managers [17]. And although senior executives have similar levels of cognitive ability [18], the use of new dynamic capabilities also requires the use of the cognitive and emotional skills of the senior management team and other critical stakeholder executives inside and outside the company [19]. The first challenge for managers will be to make effective use of dynamic managerial skills.

A changing workplace is a natural response to a pandemic crisis. Post-pandemic growth and changes in the labor market will inevitably lead to a change in some work processes. Technological innovations, such as increased informatization and automation, have reduced the need for manual work. This leads to a greater interest in artificial intelligence with a transformative effect on business [20]. There are currently a number of self-employed and globally mobile micro-enterprises that can move rapidly on demand [21]. Locationindependent digital nomads are emerging who can work from anywhere. It also changes traditional employment structures, and creates pressure to be more flexible and based on the needs of their workers. The scale of this challenge has been influenced by the need to stay in one place due to COVID-19 measures, however, the lack of innovative action to adapt the work environment in post-pandemic growth can break employers. The second challenge is to respond to the demands of workers, not only in the context of a changing workplace, but the organization of work as such.

Changing the business environment requires an appropriate strategy for recognizing opportunities. Opportunities can be described as "a stream of ever-evolving ideas driven and shaped by human social interactions, creative knowledge, and action at all times" [22]. In order for managers to succeed in the newly created dynamic environment, they must 
seize opportunities. This means focusing on employees' new social needs and using individual creativity to help employees struggle to cope with the COVID-19 crisis. According to Dimov [22], individual creativity consists of: (1) personality, (2) inner motivation, (3) knowledge and cognitive abilities. Personality refers to the general dispositions of a person. Mostly, more creative people have a personality associated with being open to new ideas. This allows them to focus on new ways of thinking [20]. Creative managers have a natural curiosity in nature that allows them to delve deeper into new problems. They are prone to innovation and risk. Internal motivation is one of the reasons why some individuals may recognize certain opportunities better than others. The need for success can be a motivating factor that pushes individuals into creative activities. Knowledge and cognitive abilities relate to the information available to individuals and their ability to use it [20]. We see the third challenge in creative thinking and the willingness to bear the tolerable level of risk that innovative changes bring.

The reopening of workplaces thus brings challenges that will lead to "physical" and technological changes such as ensuring safety in the workplace, the introduction of new digital technologies, test stations and so. From our point of view, however, the second group of changes, which we can call behavioral, appears to be more important. "Physical" changes can only go as far as the behavior of all stakeholders allows. Behavior is the root of pandemic management and will continue to be root after it has passed. Therefore, we consider the most important challenge to be motivating and maintaining behavior, which will ensure the company not only a safe resumption of operations, but will support the management of all the above challenges and contribute to increasing the competitiveness of the organization.

The challenge seems even more important in the context of the increasingly common term "behavioral fatigue" by experts [23]. Behavioral fatigue can cause people exposed to long-term regulatory behavior to gradually disregard regulations. This leads to undesirable patterns of behavior [24]. Behavioral fatigue can also be transferred to the organizational behavior of employees. One possibility is that behavioral fatigue results from "ego depletion." According to this theory, self-control is similar to a muscle that can be tired $[25,26]$. Therefore, if people need self-control to comply with government regulations, they may be violated over time because they run out of psychic power. However, extensive attempts to replicate the findings on which the theory of ego depletion is based have failed [27], but this does not disprove the existence of behavioral fatigue. On the contrary, several studies empirically prove this [28-30]. Whether this phenomenon is real or not has not yet been resolved. But we think that individual "disobedience" can endanger and motivate all the workers involved, causing fear and stress. The key challenge, therefore, is to understand the behavior of members of the organization and to be able to successfully motivate them. Only in this way can the manager effectively manage the organization for a successful reopening.

\section{Research design}

The aim of the theoretical research is to point out the possible effects of the pandemic crisis on the social environment through professional literature and scientific articles. The object of the theoretical research is the changes in human behavior caused by the current situation. We focus mainly on deviations from what normative theories consider rational behavior. We explain how a change in conditions affects people's decisions and actions and how they change their organizational behavior. We extract from the literature those changes and challenges in the field of organizational behavior of employees, to which the knowledge of behavioral economics allows us to respond more flexibly. 
To analyze the topic, we used available domestic and foreign sources that describe the organizational behavior of people, changes in the social environment due to the pandemic and list the challenges that these changes will bring to managerial practice. By processing the information obtained, we create the clearest possible picture of the reality that managers will have to face in the near future.

To process the theoretical part of the work, we used the basic methods of research: analysis, synthesis, generalization, induction and deduction. Based on theoretical knowledge, we solved the following research questions in the practical part:

- What deviations from rational behavior can managers expect in a post-pandemic work environment?

- How does behavioral economics explain these differences?

- How can managers use the knowledge of behavioral economics to ensure the required behavior of employees and thus more effectively face new management challenges?

We answered the answers to the research questions as part of the results and discussion of our work.

\section{Research results and discussion}

\subsection{The contribution of knowledge of behavioral economics in reopening}

Behavioral economics develops an ever-widening range of phenomena in human behavior. In the English literature on decision-making and behavior, we encounter the word "bias", whose literal meaning is inclination, deviation, prejudice, and the like. To explain the meaning, it seems more appropriate to start from the publication by V. Bačová, which refers to the work of M. Šinský, where he states that "prone to error is a free translation of the English word" bias "and expresses the difference between actual action (description) and prediction of certain normative models'. In his understanding, the propensity for error includes a tendency/inclination to make wrong decisions on a systematic and predictable basis [31].

In our work, we will address 6 selected tendencies to errors that, in our opinion, are related to behavior affected by COVID-19. We believe that this knowledge can help managers respond properly to changes in the behavior of members of the organization where they work. We focused on the following propensity for mistakes: bias by presence, bias in the status quo, framing effect, exaggerated optimism and self-confidence, affective heuristics and herd behavior. We will try to explain each of these preconceptions on the basis of the available literature. It should be noted that the nomenclature of these terms may differ from author to author in domestic literature. We have decided to use the terms that, in our opinion, best describe the meaning of the terms. We will describe the error tendencies in the context of the COVID-19 pandemic. We believe that they will help the reader to understand why people do not act in accordance with normative theories, that is, rationally. Understanding behavior will be key to its positive management in a post-pandemic economic environment.

\subsubsection{Bias by presence}

In the context that time as a parameter enters into every human decision, the costs and benefits of our choices take place at different points in time, meaning that many day-to-day decisions represent a compromise between immediate results (costs and benefits) and expected future results [32]. Presence bias or hyperbolic discounting is a nonlinear and inconsistent tendency for many individuals to prefer less benefit sooner over greater benefit 
later [32-34]. The current bias can lead to time-inconsistent preferences. An individual will make a plan for tomorrow, but once he arrives tomorrow, he may experience a change in preferences and revise his plan. For example, smoking has current benefits (temporary stress relief) as well as future costs (increased risk of lung cancer). In the case of COVID19 , for example, non-compliance with the rules may compromise the pleasure of breathing more freely without a protective mask (certain yield in the present) and an increased risk of infecting colleagues in the future (uncertain future costs). Uncertain future costs mean that not every non-wearing of the mask would lead to COVID-19 infection. So the so-called Myopic people (note myopia - myopia), who place more emphasis on the "here and now", are more likely to disregard preventive regulations to ensure workplace protection. Present bias is an explanation of why people do not behave in their best interests and why they have difficulty following beneficial preventive habits, such as safe distance in the workplace, washing their hands or wearing a protective mask [35].

Although present bias can lead to suboptimal patterns of behavior, this knowledge can also be used to provide the desired behavior. Such interventions, which represent immediate "cheap" rewards used as a way to increase immediate benefits from, for example, weight loss [36] or smoking cessation [37], have been shown to be effective in desired behavior change. In the short term, it is possible to increase workplace safety, for example by benefiting from a package of protective equipment, introducing free internet for employees who can work from home, or immediate reward for employees who are willing to continue working at home in case of a serious illness. It is up to the manager to evaluate the situation in his organization. Properly chosen immediate small and inexpensive rewards can lead to the desired change in behavior and bring a much greater benefit to the company in the future.

\subsubsection{Bias in the status quo}

The status quo bias is a disproportionate preference for the current situation among the options of the decision-maker and a reluctance to change this situation [38]. One reason is that people interpret the potential disadvantages of changing the current situation more strongly than the potential benefits of changing. However, thanks to the studies of behavioral economists, this reluctance can be turned into an advantage through the socalled "nudge". The concept of "nudges" was introduced in the behavioral economy to persuade individuals to behave rationally and make better decisions. Thaler and Sunstein [39] defined "nudging" as "any aspect of the architecture of choice that predictably influences individual decision-making without forbidding any options or changing economic incentives.", what they call the "architecture of choice," individuals may be influenced to make more reasonable decisions. The selection architecture can be used to create an environment in which it is easier to make optimal choices and more difficult to select suboptimal ones. The most appropriate option is to poke with a strong impact on guiding people's behavior in ways that suit their own long-term interests [39]. One of the most significant examples of "nuging" in practice is organ donation. Countries with an optout system (organ donation is assumed and organ donation is the default), have significantly higher rates of organ donation than opt-in countries (organ donation is not the default) [40]. Workplace COVID-19 prevention measures can also encourage people to engage in preventive behaviors, such as hand disinfection, by arranging default settings in the environment in which they work. An example could be the installation of disinfectant dispensers in suitable places in the workplace, e.g. at the entrances to buildings. 


\subsubsection{Framing effect}

The framing effect relates to the fact that individuals' decisions often depend on the way in which the options are presented, and that decisions are often influenced by whether possible outcomes are designed in terms of profits or losses [41]. This concept is closely linked to the aversion to losses, which implies that the subjective perception of a reduction in utility from a particular amount of loss is about twice that of profit from the same amount. For example, the statements "the probability of surviving after 1 month of surgery is $90 \% "$ and "the probability of death within 1 month of surgery is $10 \%$ " elicit different reactions. Both statements provide the same information, but many people respond differently to the risk of surgery, with a $90 \%$ chance of survival versus a $10 \%$ chance of death [42].

This knowledge provides a perspective for formulating reports on workplace measures. It seems that messages designed to encourage people to take preventive behavior during COVID-19 (eg social distancing) should be worded in terms of losses, such as "If you do not wash your hands properly / If you do not follow the principles of social distance / If you do not wear a veil on workplace, we will be forced to suspend operations and reduce yearend remuneration. "However, this is not entirely true. This may be related to the demotivation of employees, who may perceive the reports formulated in this way as threatening. Unwanted pressure may be exerted on them, and therefore in this case it is more suitable e.g. "nudging" technique. However, the situation is different for healthrelated reports. Here, studies have shown that most people respond better to positive information in the sense of "If you follow anti-pandemic measures, you will protect you and your family and have a happy and long life [43]." It is up to the creativity and discretion of the manager to use this knowledge in specific situations in the workplace.

\subsubsection{Exaggerated optimism and self-confidence}

N.D. Weinstein found that people are unrealistically optimistic about the wide range of possible negative consequences of their actions and feel less than on average at risk of negative outcomes in their own lives [44]. Exaggerated optimism is the tendency of people to estimate the probability of positive future results as above average and the probability of negative future results as below average [45]. This can lead people to inadvertently take more risks than they would if they were aware of objective risk [46]. Exaggerated optimism helps explain a wide range of risky behaviors. For example, one study found that smokers significantly underestimated the risk of developing lung cancer compared to the risk of lung cancer in other smokers and even non-smokers [47]. Another similar study found that people at a subjective risk lower than the objective risk are more likely to believe that there is no risk of lung cancer if you smoke for only a few years, and believe that a large number of lung cancer patients will be cured [ 48].

People are aware of the risk of getting COVID-19 in suboptimal behaviors, such as not washing their hands or keeping their distance, but they probably believe that they are less likely than other people. In addressing such behavior, it is essential to provide quality feedback with accurate risk communication. It is good for people to illustrate possible risks and their effects with examples. Examples should be strong, which can be achieved by presenting the consequences of negative behavior on people like them (similar social group, age, status) who did not behave optimally [49]. Patterns are also a good example. We can achieve preventive behavior, for example, by pointing out that the same problem also applies to popular celebrities, and negative consequences have not been avoided even for people whose employees consider them to be of better quality than themselves. 


\subsubsection{Affective heuristics}

Affective heuristics examine the commonly observed inverse relationship between perceived risk and perceived benefit. People rely on "affect" to assess the risk and benefit of a particular hazard [50]. Affective heuristics is a type of mental acronym in which people make decisions that are strongly influenced by their current emotions [51]. Emotions affect all types of decisions, big and small. A person is more likely to take risks or try new things when they are happy and less likely to reach a goal when they are troubled. Managing "inner feeling" is what behavioral economists call affective heuristics [52]. People's feelings about the relative "goodness" or "evil" of a particular person, object, or activity influence the decisions they ultimately make. Researchers have found that in a positive emotional state, a person is more likely to perceive their actions as an activity that brings high benefits and low risks [50]. When the emotional state is negative, people are inclined to believe that the decision will bring them low benefits associated with high risk. The study by Fischhoff et al. from 1978 plays an important role in the study of affective heuristics. Researchers have found that the perception of benefits and risks has been negatively correlated - the greater the perceived utility, the lower the perceived risk [53]. At the same time, it seems that the riskier the behavior, the less perceived the benefits. Certain behaviors, such as drinking alcohol and smoking, are considered high-risk and low-benefit, while other things, such as antibiotics and vaccines, are considered high-benefit and lowrisk. Researchers have also found that emotions can also affect people's judgments about statistical information. In one study, patient recurrence rates were presented to clinicians, which were presented as either a probability (e.g., 30\%) or a frequency (e.g., 30 out of 100). The study showed that physicians made more extreme judgments about the risk of recurrence when presented as a frequency [54]. This is because they see an absolute number behind the frequency, which for them means 30 people who have returned to disease behavior. This is also related to the already mentioned tendency to framing. Information in different forms can evoke different emotions and thus influence decisions.

According to the above findings, managers can purposefully evoke emotions associated with the behavior of employees in the workplace. The meaning of heuristics is that they make it possible to reduce the time needed to make a decision, by making this decision based on immediate emotion. If the manager is able to create positive emotions in the employees associated with the desired behavior, the employee will repeat these patterns of behavior naturally, without a deeper analytical assessment of the impact of his actions and will believe that he is doing the right thing.

\subsubsection{Herd behavior}

Social norms and the behavior of social groups, such as friends, family members and colleagues, influence the behavior of individuals. Herdiness occurs when people consider certain behaviors to be good or bad and mimic the observed behavior [55]. This characteristic of human behavior is observable in many areas, especially in economics and finance [56]. An experiment from Minnesota is well known, which proves this phenomenon empirically. Minnesota residents reported that more than $90 \%$ of Minnesotans paid taxes. This information had a significant impact on tax compliance. The effect of herd behavior was more pronounced than the other interventions used [39,57].

If a manager wants to encourage people to follow the required regulations, he should draw their attention to the group of people who do so. For example, informing people that everyone in the workplace is following the rules in an exemplary way can increase the motivation to follow the measures even for people who do not fully identify with their content. 


\subsection{Discussion}

The COVID-19 pandemic with the onset of global vaccination may appear to be slowly fading, but its effects are beginning to show very slowly. Turbulent technological transformation, often forced innovation, new challenges and obstacles require original solutions. The economic, legal, social, technological and environmental environment is significantly transformed as a result of the pandemic. The pandemic has caught the world unprepared. All the more important is the ability to adapt quickly to new conditions. In addition to the problems, the pandemic will bring many opportunities. How managers respond to the challenges will be a determining factor in the success of companies in the post-pandemic era. Their skills and knowledge will determine the success of the organizations they represent. Every organization is based on the people who make it up. The importance of human capital continues to grow even in a period of raging pandemic, and we can assume that it will be even more pronounced after it erupts.

We can expect attempts to reopen workplaces in the near future. The same employees may return to their jobs, but the change in the country's social climate has meant that they can take different positions, behave according to new patterns of behavior, experience some emotions more intensely and act differently than we were used to before the crisis. How do managers deal with changes in employee behavior? Can they effectively manage people in new specific situations? A strategic approach to management requires leaders to respond to change with change. It is likely that the management approaches that worked in pre-crisis organizations will begin to appear ineffective and ineffective. Achieving the desired employee behavior will be one of the key challenges for managers when reopening.

Behavioral economics examines changes in organizational behavior, decision-making processes, human thinking, and action. We think that her knowledge can help managers manage new situations in connection with the behavior and actions of employees very effectively. Behavioral economics develops human behavior in specific situations and uses descriptive and prescriptive examination of decision-making in combination with the knowledge of psychology to be able to justify it. It is the behavioral economy that gives us the tools to understand human action. Understanding is the first step for a manager to be able to manage this behavior effectively.

In the final chapters, we present to managers selected findings of behavioral science, which we consider useful in their response to possible changes in organizational behavior that COVID-19 may have induced. We would be happy if we provoke a discussion on the topic of managing deviations in behavior in the post-pandemic era in Slovakia. The basis of behavioral economics is to investigate the issue by experiment. It is the scientific experiments, many of which we have mentioned, that help us to understand the issue of behavior. In Slovakia, too, we can find many experts who deal with the topic on a theoretical level. However, there is no empirical research that would examine the hypotheses of behavioral economics in the Slovak business environment. We believe that this gap will gradually begin to fill and the key importance of behavior in the postpandemic world will encourage many Slovak experts to contribute to scientific work in the field of behavioral economics.

At the end of the discussion, we consider it necessary to defend a large number of sources of used literature. The knowledge of behavioral economics is mainly based on knowledge gained epmirically through economic and social experiments. The topic and the nature of the work imply the need to refer to several empirical researches to the individual knowledge, which empirically confirm this knowledge. Reducing the number of used sources of literature would reduce the value of the work and the empirically obtained knowledge would become unsubstantiated claims. We believe that in order to preserve the added value of the contribution, the reader will forgive us. 


\section{Conclusion}

Based on our examination we can state a few conclusions. Recent research and available data confirm that we will see a number of changes in management practice as a result of the pandemic. The technological, social, economic, political and environmental environment is changing. These changes are coming more or less expected. It is the task of managers to respond to them and be able to eliminate threats on the one hand and seize opportunities on the other. One of the changes we can expect is a change in organizational behavior. Recent research suggests that the psychological pressure created by current crisis conditions will lead to a variety of undesirable variations in the behavior of individuals and groups. Every change means a challenge for the manager. Behavioral economics examines these deviations and its findings allow managers to prepare and respond more flexibly.

Managers will need to start using their dynamic skills. Creativity in management will be one of the key competencies in managing the new demands of employees. Only in this way can the manager respond to new requests from employees for work organization. What may have seemed like a benefit before the pandemic can already be considered a standard by employees. Managers will be required to be willing to take the risk of introducing innovations. However, several new measures and innovations can create reluctance among employees. The psychological pressure that we all experience through a pandemic has a demonstrable effect on people's organizational behavior. The most key challenge, therefore, is to understand the behavior of the members of the organization and to be able to successfully motivate them. Only in this way can the manager effectively manage the organization for a successful reopening.

In the theoretical part of the paper, we gained knowledge about possible changes in the environment. In the practical part, we looked for an answer to the question of what effect these changes will have on behavior. The authors of behavioral science have researched the issue of human crisis behavior in the past. From their empirically obtained knowledge, after considering, we selected 6 deviations from rational, normative behavior. For each of the "biases", we looked in the available literature as an example and a proposal for a solution. This solution was not always from a managerial environment. Analogously, however, we searched for and created a model example, on which we would be able to apply the acquired knowledge to managerial practice by analogy. The solutions are presented in the practical part of the work for each of the "biases" and allow managers to manage, eliminate and often evaluate threats resulting from changes in organizational behavior. Behavioral economics uses descriptive approaches to describe behavior. The combination of economics, decision-making science and psychological disciplines explains the described behavior. This allows the manager to understand this behavior. If the manager gains knowledge about what can cause the occurrence of undesirable patterns of behavior in the workplace, he can rather detect these patterns and respond to them. This contributes to the establishment of the right organizational culture, increases the safety of workers, leads to the elimination of unnecessary conflicts that negatively affect labor productivity. Only a manager who understands employee behavior can become a true leader in a post-pandemic company. And we are confident that the resurgenting economy will definitely need true leaders.

\section{Acknowledgement}

This paper is a partial output of the VEGA ME SR project No.1/0017/20 Changes in the application of managerial functions in the context of the fourth industrial revolution and adaptation processes of enterprises in Slovakia. 


\section{References}

1. WHO, WHO Coronavirus (COVID-19) Dashboard, (2021). https://covid19.who.int (accessed April 19, 2021).

2. M.C. Howard, Understanding face mask use to prevent coronavirus and other illnesses: Development of a multidimensional face mask perceptions scale, Br J Health Psychol. (2020). https://doi.org/10.1111/bjhp.12453.

3. L. Ferretti, C. Wymant, M. Kendall, L. Zhao, A. Nurtay, L. Abeler-Dörner, M. Parker, D. Bonsall, C. Fraser, Quantifying SARS-CoV-2 transmission suggests epidemic control with digital contact tracing, Science, 368 (2020). https://doi.org/10.1126/science.abb6936.

4. A. Baveja, A. Kapoor, B. Melamed, Stopping Covid-19: A pandemic-management service value chain approach, Ann Oper Res., 1-12 (2020). https://doi.org/10.1007/s10479020-03635-3.

5. M.P. Crayne, The traumatic impact of job loss and job search in the aftermath of COVID-19, Psychol Trauma, 12, 180-182 (2020). https://doi.org/10.1037/tra0000852.

6. M.B. Omary, J. Eswaraka, S.D. Kimball, P.V. Moghe, R.A. Panettieri, K.W. Scotto, The COVID-19 pandemic and research shutdown: staying safe and productive, J Clin Invest., 130, 2745-2748 (2020). https://doi.org/10.1172/JCI138646.

7. IMFBlog, The Great Lockdown: Worst Economic Downturn Since the Great Depression, IMF Blog. (2020). https://blogs.imf.org/2020/04/14/the-great-lockdown-worsteconomic-downturn-since-the-great-depression/ (accessed April 19, 2021).

8. E. Aguila, Personal Retirement Accounts and Saving, Am Econ J Econ Policy, 3, 124 (2011). https://doi.org/10.1257/pol.3.4.1.

9. M. Griffin, S. Tippins, A case study exploration of blue-collar worker retirement plan investment decisions, International Journal of Applied Management and Technology, 15 (2016) 3.

10. A.E. Sunden, B.J. Surette, Gender differences in the allocation of assets in retirement savings plans, The American Economic Review, 88, 207-211 (1988).

11. A. Goolsbee, C. Syverson, Fear, lockdown, and diversion: Comparing drivers of pandemic economic decline 2020, Journal of Public Economics, 193 (2021) 104311.

12. C.-C. Topriceanu, A. Wong, J.C. Moon, A.D. Hughes, N. Chaturvedi, G. Conti, D. Bann, P. Patalay, G. Captur, Impact of lockdown on key workers: findings from the COVID-19 survey in four UK national longitudinal studies, J Epidemiol Community Health. (2021). https://doi.org/10.1136/jech-2020-215889.

13. Mesto Nitra, Mesto Nitra - Prípady nerešpektovania nariadení sa opakujú, (2021). https://www.nitra.sk/zobraz/obsah/33325 (accessed April 19, 2021).

14. K. Piovarcsy, Covid-19 spôsobí vel'kú vlnu protestov po celom svete, (2020). https://www.trend.sk/nazory-a-komentare/covid-19-sposobi-velku-vlnu-protestov-celomsvete (accessed April 19, 2021).

15. A.D. Meyer, G.R. Brooks, J.B. Goes, Environmental jolts and industry revolutions: Organizational responses to discontinuous change, Strategic Management Journal, 93-110 (1990).

16. M.A. Hitt, J. Arregle, R.M. Holmes, Strategic Management Theory in a Post-Pandemic and Non-Ergodic World, Journal of Management Studies. (2020). https://doi.org/10.1111/joms. 12646.

17. R. Adner, C.E. Helfat, Corporate effects and dynamic managerial capabilities, Strategic Management Journal, 24, 1011-1025 (2003).

18. M.A. Hitt, B.B. Tyler, Strategic decision models: Integrating different perspectives, Strategic Management Journal, 12, 327-351 (1991). 
19. G.P. Hodgkinson, M.P. Healey, Psychological foundations of dynamic capabilities: Reflexion and reflection in strategic management, Strategic Management Journal. 32 (2011) 1500-1516.

20. V. Ratten, Coronavirus (covid-19) and entrepreneurship: changing life and work landscape, Journal of Small Business \& Entrepreneurship. 32 (2020) 503-516. https://doi.org/10.1080/08276331.2020.1790167.

21. M. Ahsan, Entrepreneurship and Ethics in the Sharing Economy: A Critical Perspective, J Bus Ethics. 161 (2020) 19-33. https://doi.org/10.1007/s10551-018-3975-2.

22. D. Dimov, From opportunity insight to opportunity intention: The importance of person-situation learning match, Entrepreneurship Theory and Practice. 31 (2007) 561583.

23. N. Harvey, Behavioral Fatigue: Real Phenomenon, Naïve Construct, or Policy Contrivance?, Front Psychol. 11 (2020). https://doi.org/10.3389/fpsyg.2020.589892.

24. A. vaughanbell, Do we suffer 'behavioural fatigue' for pandemic prevention measures?, Mind Hacks. (2020). https://mindhacks.com/2020/03/20/do-we-sufferbehavioural-fatigue-for-pandemic-prevention-measures/ (accessed April 20, 2021).

25. R.F. Baumeister, E. Bratslavsky, M. Muraven, D.M. Tice, Ego depletion: is the active self a limited resource?, J Pers Soc Psychol. 74 (1998) 1252-1265. https://doi.org/10.1037//0022-3514.74.5.1252.

26. R.F. Baumeister, Ego depletion and self-control failure: An energy model of the self's executive function, Self and Identity. 1 (2002) 129-136.

27. M.S. Hagger, N.L. Chatzisarantis, H. Alberts, C.O. Anggono, C. Batailler, A.R. Birt, R. Brand, M.J. Brandt, G. Brewer, S. Bruyneel, A multilab preregistered replication of the ego-depletion effect, Perspectives on Psychological Science. 11 (2016) 546-573.

28. J. Drury, H. Carter, E. Ntontis, S.T. Guven, Public behaviour in response to the COVID-19 pandemic: understanding the role of group processes, BJPsych Open. 7 (2021) e11. https://doi.org/10.1192/bjo.2020.139.

29. H. Rahmandad, T.Y. Lim, J. Sterman, Behavioral dynamics of COVID-19: estimating under-reporting, multiple waves, and adherence fatigue across 91 nations, MedRxiv. (2020).

30. S. Reicher, J. Drury, Pandemic fatigue? How adherence to covid-19 regulations has been misrepresented and why it matters, BMJ. 372 (2021) n137. https://doi.org/10.1136/bmj.n137.

31. V. Bačová, Rozhodovanie a usudzovanie II, Oblasti a Koncepcie. Bratislava, Ústav Experimentálnej Psychológie SAV. (2011).

32. T. O'Donoghue, M. Rabin, Present bias: Lessons learned and to be learned, American Economic Review. 105 (2015) 273-79.

33. D. Laibson, Golden Eggs and Hyperbolic Discounting, The Quarterly Journal of Economics. 112 (1997) 443-77. https://doi.org/10.1162/003355397555253.

34. G. Loewenstein, D.A. Asch, J.Y. Friedman, L.A. Melichar, K.G. Volpp, Can behavioural economics make us healthier?, Bmj. 344 (2012).

35. M. Van Der Pol, D. Hennessy, B. Manns, The role of time and risk preferences in adherence to physician advice on health behavior change, The European Journal of Health Economics. 18 (2017) 373-386.

36. L.K. John, G. Loewenstein, A.B. Troxel, L. Norton, J.E. Fassbender, K.G. Volpp, Financial incentives for extended weight loss: a randomized, controlled trial, Journal of General Internal Medicine. 26 (2011) 621-626.

37. S.D. Halpern, B. French, D.S. Small, K. Saulsgiver, M.O. Harhay, J. AudrainMcGovern, G. Loewenstein, T.A. Brennan, D.A. Asch, K.G. Volpp, Randomized trial of four financial-incentive programs for smoking cessation, N Engl J Med. 372 (2015) 21082117. 
38. W. Samuelson, R. Zeckhauser, Status quo bias in decision making, Journal of Risk and Uncertainty. 1 (1988) 7-59.

39. R.H. Thaler, C.R. Sunstein, Nudge: improving decisions about health, wealth, and happiness, Yale University Press, New Haven, 2008.

40. E.J. Johnson, D. Goldstein, Do Defaults Save Lives?, Science. (2003). https://doi.org/10.1126/SCIENCE.1091721.

41. D. Kahneman, A. Tversky, Prospect Theory: An Analysis of Decision under Risk, Econometrica. 47 (1979) 263-291. https://doi.org/10.2307/1914185.

42. J. Luoto, K.G. Carman, Behavioral economics guidelines with applications for health interventions, Washington DC: Inter-American Development Bank. (2014).

43. K.M. Gallagher, J.A. Updegraff, Health message framing effects on attitudes, intentions, and behavior: a meta-analytic review, Annals of Behavioral Medicine. 43 (2012) $101-116$.

44. N.D. Weinstein, Unrealistic optimism about future life events., Journal of Personality and Social Psychology. 39 (1980) 806.

45. N.D. Weinstein, Unrealistic optimism about susceptibility to health problems: conclusions from a community-wide sample, J Behav Med. 10 (1987) 481-500. https://doi.org/10.1007/BF00846146.

46. C.A. Roberto, I. Kawachi, eds., Behavioral economics and public health, Oxford University Press, Oxford; New York, 2016.

47. N. Weinstein, S. Marcus, R. Moser, Smokers' unrealistic optimism about their risk, Tob Control. 14 (2005) 55-59. https://doi.org/10.1136/tc.2004.008375.

48. A.J. Dillard, K.D. McCaul, W.M.P. Klein, Unrealistic Optimism in Smokers: Implications for Smoking Myth Endorsement and Self-Protective Motivation, Journal of Health Communication. 11 (2006) 93-102. https://doi.org/10.1080/10810730600637343.

49. J.L. Matjasko, J.H. Cawley, M.M. Baker-Goering, D.V. Yokum, Applying Behavioral Economics to Public Health Policy: Illustrative Examples and Promising Directions, American Journal of Preventive Medicine. 50 (2016) S13-S19. https://doi.org/10.1016/j.amepre.2016.02.007.

50. M.L. Finucane, A. Alhakami, P. Slovic, S.M. Johnson, The affect heuristic in judgments of risks and benefits, Journal of Behavioral Decision Making. 13 (2000) 1-17. https://doi.org/10.1002/(SICI)1099-0771(200001/03)13:1<1::AID-BDM333>3.0.CO;2-S.

51. P. Slovic, M.L. Finucane, E. Peters, D.G. MacGregor, The affect heuristic, European $\begin{array}{llllll}\text { Journal of Operational } & \text { Research. } & 177 & \text { (2007) } & 1333-1352 .\end{array}$ https://doi.org/10.1016/j.ejor.2005.04.006.

52. J.S. Lerner, Y. Li, P. Valdesolo, K.S. Kassam, Emotion and Decision Making, Annu. Rev. Psychol. 66 (2015) 799-823. https://doi.org/10.1146/annurev-psych-010213-115043.

53. K.T. Fox-Glassman, E.U. Weber, What makes risk acceptable? Revisiting the 1978 psychological dimensions of perceptions of technological risks, Journal of Mathematical Psychology. 75 (2016) 157-169. https://doi.org/10.1016/j.jmp.2016.05.003.

54. V.F. Reyna, W.L. Nelson, P.K. Han, N.F. Dieckmann, How numeracy influences risk comprehension and medical decision making., Psychological Bulletin. 135 (2009) 943-973. https://doi.org/10.1037/a0017327.

55. D. Ariely, Predictably Irrational, Revised and Expanded Edition: The Hidden Forces That Shape Our Decisions, Revised and Expanded ed. edition, Harper Perennial, New York, NY, 2010.

56. R.M. Raafat, N. Chater, C. Frith, Herding in humans, Trends in Cognitive Sciences. 13 (2009) 420-428. https://doi.org/10.1016/j.tics.2009.08.002.

57. S. Coleman, The Minnesota Income Tax Compliance Experiment--State Tax Results, Social Science Research Network, Rochester, NY, 1996. https://papers.ssrn.com/abstract=4419 (accessed April 20, 2021). 